\title{
UTILIZATION OF UV RADIATION FOR THE IMPROVEMENT OF ECONOMIC TRAITS IN THE SILKWORM, BOMBYX MORI L.
}

\author{
Md. Jamsed Ali, Sawdagar Mahfuzar Rahman, Saiful Islam Faruki and Md. Kamrul Ahsan* \\ Sericulture Research Laboratory, Department of Zoology, University of Rajshahi, Rajshahi 6205, \\ Bangladesh \\ *Corresponding author(email: md_kahsan@ru.ac.bd)
}

\begin{abstract}
To detect the effect of ultraviolet (UV) radiation on some economic traits of the silkworm, Bombyx mori L. variety Urboshi-1, 5-day old pupae were irradiated with $366 \mathrm{~nm}$ wavelength of UV-rays at a distance of $10.6 \mathrm{~cm}$ for $1,5 \mathrm{and} 10 \mathrm{~min}$. UVradiation had significant effects on majority of the 16 characters considered for the study. Three different lines viz. U1-DW, U1LW and U10-LD were isolated on the basis of their cocoon shape and size from the rearing of the $1^{\text {st }}$ radiated generation $\left(R_{1}\right)$. The rearing of the $R_{2}$ generation produced cocoons which conformed to the shape and size of the cocoons as selected in the $R_{1}$ generation. The selected lines showed better rearing performance than the control for majority of the characters, especially the cocoon characters which had direct relationships with the commercial cocoon production. Cocoons produced in the $\mathrm{R}_{2}$ generation were utilized in the $R_{3}$ generation. The evaluation of the cocoon characters of the $R_{3}$ generation revealed that U1-LW and U10LD lines hold promise for commercial exploitation. Moreover, U10-LD also showed the lowest larval mortality.
\end{abstract}

Key words: UV-rays, economic traits, Bombyx mori.

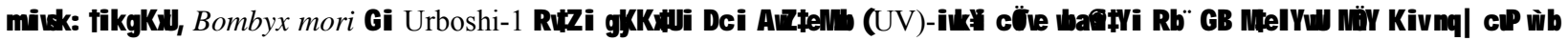

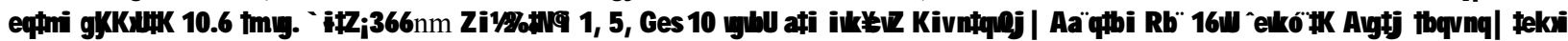

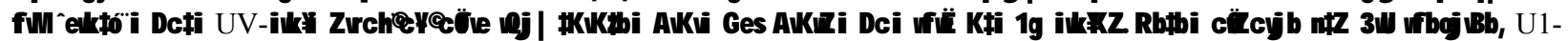

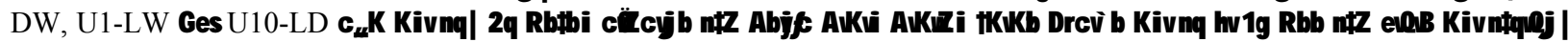

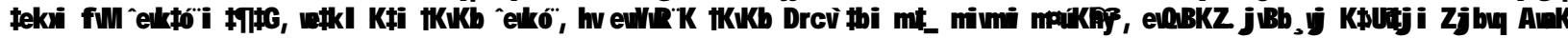

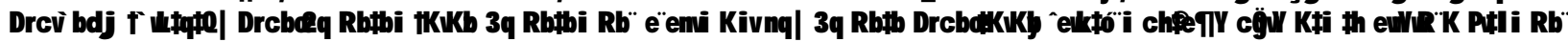

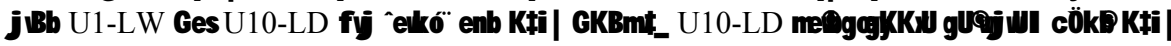

\section{Introduction}

Research on the mutagenic action of ultraviolet (UV) rays started soon after the discovery of X-ray mutagenesis. Altenburg (1934) was first to discover the mutagenic effect of UV rays on the polar cap cells in Drosophila melanogaster. Experiments with UV rays show that they do not possess sufficient energy to induce ionization (Levine 1980). Subsequently, it has been demonstrated that like Xrays, UV radiations produce point mutations, small deficiencies, chromosome breaks and chromosome rearrangements at different relative frequencies in many organisms. However, investigations reveal that radiosensitivity varies according to the species, strains, individuals and even in different developmental stages of the same species (Gardner and Snustad 1981; Singh et al. 1990; Hasan et al. 1998; Faruki 2004; Faruki and Kundu 2005). Tazima $(1983,1984)$ also reported the significant effect of chemical mutagen and ionizing radiation on B. mori.

Though majority of radiation-induced mutations are more or less harmful to the organisms, beneficial mutations can be induced by radiation and extensive breeding work with plants on radiation breeding has yielding many useful mutants (Aurbach, 1976). Tazima
(1964), Mallik et al. (1968), Coulon (1969), Kotani et al. (2002) and Hosagoudar and Manjunatha (2006) worked with ultraviolet-, infrared-, X- and $\gamma$-rays on different developmental stages in $B$. mori and on different aspects of its biology. In addition, a number of researchers namely Sengupta et al. (1973), Datta and Roy (1976) and Sengupta et al. (1977) carried out experiments on X-ray and $\gamma$-ray induced mutagenesis to improve their local silkworm races and they also recorded positive results at low doses of irradiation. Recently, Hosagoudar and Manjunatha (2011) investigated the effect of picosecond UV laser radiation on morphological, biochemical and biological changes of silkworm, Bombyx mori.

Urboshi-1 is an evolved variety of mulberry silkworm in our country. As the quantitative traits of silkworm variety are mostly controlled by polygenes, it is presumed that new genetic variability to the gene pool of $B$. mori can be added by applying radiation treatment at different developmental stages (Sengupta et al. 1973). The present investigation was therefore undertaken to find out the effects of UV-radiation on some quantitative traits of this multivoltine silkworm variety. 


\section{Materials and methods}

Experimental animal and irradiation: The experimental materials of 5-day old male and female pupae of Urboshi-1 B. mori L. (Lepidoptera: Bombycidae) were procured from the Germplasm Bank of the Bangladesh Sericulture Research and Training Institute (BSRTI), Rajshahi. The pupae were exposed to $366 \mathrm{~nm}$ wavelength of UV-ray at three different durations viz. 1, 5 and $10 \mathrm{~min}$ from a distance of $10.6 \mathrm{~cm}$ in each case. A $15 \mathrm{~W}$ germicidal lamp, GE15T 8 measuring $20 \times 4 \mathrm{~cm}$ was the source of UV radiation, emitting at a wavelength of $366 \mathrm{~nm}$. The irradiation was carried out at the Genetic Engineering Laboratory, Department of Zoology, Rajshahi University. The male and female moths that emerged from the treated pupae were mated. Eggs were collected on egg cards for next rearing. Silkworm larvae were reared following the techniques described Krishnaswami (1978) and Rahman (1983). A single batch of non-irradiated worms was simultaneously reared on fresh mulberry leaves as the control. The experiment was replicated thrice.

Isolation: On the basis of weight, shape and size of cocoons recovered from UV-radiated $\mathrm{R}_{1}$ generation three different lines were isolated as follows: (1) U1DW, selected from 1 min treatment and had dumbbell shaped cocoon provide with wrinkles; (2) U1-LW, also selected from 1 min dose of UV-radiation but the cocoons had long with round tips; and (3) U10-LD, selected from $10 \mathrm{~min}$ UV treatment that had long cocoons with depression in the middle.

Table 1. Effect of UV-radiation on the economic traits of a multivoltine variety (Urboshi-1) of the silkworm B. mori.

\begin{tabular}{|c|c|c|c|c|c|}
\hline \multirow{2}{*}{ Traits } & \multicolumn{4}{|c|}{ Doses of UV-radiation (min) } & \multirow{2}{*}{ F-values } \\
\hline & 1 & 5 & 10 & 0 (Control) & \\
\hline LW-3 & $117.8 \pm 1.789$ & $129.70 \pm 0.321$ & $132.97 \pm 1.675$ & $98.73 \pm 0.578$ & $214.04 * *$ \\
\hline LW-4 & $398.37 \pm 3.578$ & $383.93 \pm 2.764$ & $376.97 \pm 1.920$ & $369.03 \pm 2.699$ & $17.56^{* *}$ \\
\hline LW-5 & $508.66 \pm 0.821$ & $465.50 \pm 5.953$ & $512.90 \pm 3.477$ & $466.80 \pm 4.833$ & $31.48 * *$ \\
\hline LW-M & $1522.57 \pm 15.740$ & $1407.00 \pm 54.87$ & $1300.93 \pm 19.01$ & $1376.60 \pm 20.917$ & $8.29 *$ \\
\hline LL-4 & $31.13 \pm 0.145$ & $31.46 \pm 0.133$ & $31.06 \pm 0.384$ & $28.90 \pm 0.251$ & $17.25 * *$ \\
\hline LL-5 & $50.67 \pm 0.240$ & $48.70 \pm 1.147$ & $47.67 \pm 0.240$ & $43.93 \pm 0.982$ & $10.85 * *$ \\
\hline LL-M & $50.67 \pm 0.240$ & $47.70 \pm 1.171$ & $47.67 \pm 0.240$ & $43.93 \pm 0.982$ & $10.90 * *$ \\
\hline LM & $38.33 \pm 1.666$ & $43.66 \pm 0.881$ & $35.66 \pm 2.333$ & $41.33 \pm 0.666$ & $4.12 \mathrm{~ns}$ \\
\hline $\mathrm{CW}$ & $1027.56 \pm 4.909$ & $927.37 \pm 26.274$ & $925.80 \pm 18.885$ & $851.07 \pm 23.613$ & $16.15 * *$ \\
\hline SW & $135.63 \pm 2.744$ & $125.80 \pm 3.017$ & $125.13 \pm 1.162$ & $112.47 \pm 0.057$ & $14.52 * *$ \\
\hline $\mathrm{SR} \%$ & $0.127 \pm 0.0004$ & $0.119 \pm 0.0003$ & $0.126 \pm 0.0008$ & $0.129 \pm 0.0005$ & $5.00 *$ \\
\hline $\mathrm{CL}$ & $30.53 \pm 0.352$ & $28.90 \pm 0.458$ & $27.73 \pm 0.508$ & $28.30 \pm 0.200$ & $7.06^{*}$ \\
\hline CB & $14.07 \pm 0.284$ & $14.10 \pm 0.115$ & $15.03 \pm 0.066$ & $14.40 \pm 0$ & $0.86 \mathrm{~ns}$ \\
\hline PL & $24.13 \pm 0.384$ & $23.17 \pm 0.450$ & $23.50 \pm 0.100$ & $23.23 \pm 0.145$ & $1.66 \mathrm{~ns}$ \\
\hline $\mathrm{PB}$ & $8.67 \pm 0.120$ & $8.77 \pm 0.218$ & $8.77 \pm 0.218$ & $9.00 \pm 0.264$ & $0.35 \mathrm{~ns}$ \\
\hline PW & $981.17 \pm 0.896$ & $900.97 \pm 0.433$ & $871.07 \pm 6.970$ & $858.63 \pm 10.446$ & $64.76^{* *}$ \\
\hline
\end{tabular}

$*=5 \%$ level of significance, $* *=1 \%$ level of significance, ns $=$ not significant; weight of $3^{\text {rd }}$ instar larvae $=\mathrm{LW}-3$, weight of $4^{\text {th }}$ instar larvae $=$ LW-4, weight of $5^{\text {th }}$ instar larvae $=$ LW-5, weight of mature larvae $=$ LW-M, length of $4^{\text {th }}$ instar larvae $=$ LL-4, length of $5^{\text {th }}$ instar larvae $=$ LL-5, length of mature larvae $=$ LL-M, larval mortality $=$ LM, weight of cocoon $=$ CW, weight of shell $=\mathrm{SW}$, shell ratio $=\mathrm{SR} \%$, length of cocoon $=\mathrm{CL}$, breadth of cocoon $=\mathrm{CB}$, length of pupa $=\mathrm{PL}$, breadth of pupa $=\mathrm{PB}$, weight of pupa $=$ PW.

Parameters: The selected lines were reared for two successive generations and were designated as $\mathrm{R}_{2}$ and $\mathrm{R}_{3}$. The characters considered for the study were weight of $3^{\text {rd }}$ instar(LW-3), $4^{\text {th }}$ instar (LW-4), $5^{\text {th }}$ instar(LW-5) and mature larvae(LW-M); length of $4^{\text {th }}$ instar(LL-4), $5^{\text {th }}$ instar(LL-5) and mature larvae(LL-M); larval mortality(LM), weight of cocoon(CW) and shell(SW); shell ratio(SR\%), length(CL) and breadth(CB) of cocoon; and weight(PW), length(PL) and breadth(PB) of pupa.

Statistical procedures: Data of all the characters were subjected to analyses of variance. Here, the variance ratio $\mathrm{F}$ was calculated from the ratio between treatment mean square and residual mean square and the value was compared with the tabulated value for significance. 
Table 2. Mean performance of different lines isolated from UV-irradiated pupae of B. mori for different traits.

\begin{tabular}{|c|c|c|c|c|c|}
\hline \multirow[t]{2}{*}{ Traits } & \multicolumn{4}{|c|}{ Lines } & \multirow[t]{2}{*}{ F-values } \\
\hline & U1-DW & U1-LW & U10-LD & 0 (Control) & \\
\hline $\mathrm{CW}$ & $926.00 \pm 1.072$ & $955.00 \pm 5.507$ & $1018.67 \pm 0.88$ & $982.11 \pm 6.914$ & $59.31 * *$ \\
\hline SW & $117.11 \pm 4.655$ & $130.55 \pm 3.890$ & $130.56 \pm 3.447$ & $120.29 \pm 4.063$ & $13.65 * *$ \\
\hline $\mathrm{SR} \%$ & $0.130 \pm 0.001$ & $0.136 \pm 0.003$ & $0.134 \pm 0.003$ & $0.126 \pm 0.001$ & $2.50 \mathrm{~ns}$ \\
\hline $\mathrm{CL}$ & $29.33 \pm 0$ & $31.67 \pm 0$ & $31.55 \pm 0.399$ & $28.67 \pm 0$ & $58.75 * *$ \\
\hline $\mathrm{CB}$ & $12.12 \pm 0.293$ & $12.33 \pm 0$ & $12.67 \pm 0$ & $12.00 \pm 0.386$ & $1.44 \mathrm{~ns}$ \\
\hline $\mathrm{PL}$ & $22.67 \pm 0.193$ & $24.40 \pm 0.057$ & $22.67 \pm 0.839$ & $23.56 \pm 0.113$ & $4.43 \mathrm{~ns}$ \\
\hline PB & $9.44 \pm 0.113$ & $9.22 \pm 0.223$ & $9.78 \pm 0.11$ & $8.55 \pm 0.294$ & $6.15^{*}$ \\
\hline PW & $816.56 \pm 10.159$ & $824.33 \pm 4.599$ & $882.00 \pm 1.964$ & $865.00 \pm 0.695$ & $39.45 * *$ \\
\hline
\end{tabular}

$*=5 \%$ level of significance, $* *=1 \%$ level of significance, $\mathrm{ns}=$ not significant.

Table 3. Mean performance of different lines of $B$. mori in the $\mathrm{R}_{2}$ generation isolated from UV-irradiated pupae for different traits.

\begin{tabular}{|c|c|c|c|c|c|}
\hline \multirow[t]{2}{*}{ Traits } & \multicolumn{4}{|c|}{ Lines } & \multirow[t]{2}{*}{ F-values } \\
\hline & UI-DW & U1-LW & U10-LD & 0 (Control) & \\
\hline LW-3 & $106.11 \pm 0.986$ & $107.11 \pm 0.294$ & $99.00 \pm 1.154$ & $101.78 \pm 0.446$ & $20.93 * *$ \\
\hline LW-4 & $341.67 \pm 1.072$ & $317.11 \pm 3.443$ & $374.11 \pm 4.722$ & $376.00 \pm 1.676$ & $62.66^{* *}$ \\
\hline LW-5 & $457.11 \pm 0.775$ & $474.67 \pm 0.837$ & $485.11 \pm 0.775$ & $508.67 \pm 1.642$ & $387.91 * *$ \\
\hline LW-M & $1498.0 \pm 1.216$ & $1470.47 \pm 1.31$ & $1493.50 \pm 2.31$ & $1457.67 \pm 3.41$ & $78.00 * *$ \\
\hline LL-4 & $31.89 \pm 0.0587$ & $32.89 \pm 0.294$ & $31.33 \pm 0.510$ & $28.78 \pm 0.11$ & $15.58 * *$ \\
\hline LL-5 & $41.10 \pm 0.472$ & $42.43 \pm 0.384$ & $44.06 \pm 0.635$ & $50.87 \pm 0.669$ & $41.28 * *$ \\
\hline LL-M & $46.00 \pm 0.529$ & $49.20 \pm 0.321$ & $47.83 \pm 0.375$ & $45.13 \pm 0.578$ & $11.78 * *$ \\
\hline LM & $27.00 \pm 3.785$ & $22.33 \pm 1.201$ & $26.00 \pm 2.081$ & $30.67 \pm 2.185$ & $1.43 \mathrm{~ns}$ \\
\hline $\mathrm{CW}$ & $926.57 \pm 2.748$ & $970.50 \pm 1.357$ & $1015.33 \pm 1.848$ & $921.73 \pm 5.495$ & $144.40 * *$ \\
\hline SW & $125.90 \pm 1.417$ & $131.87 \pm 0.466$ & $141.43 \pm 0.617$ & $123.77 \pm 1.065$ & $56.02 * *$ \\
\hline SR\% & $0.138 \pm 0.001$ & $0.136 \pm 0.002$ & $0.135 \pm 0.002$ & $0.128 \pm 0.0008$ & $0.20 \mathrm{~ns}$ \\
\hline $\mathrm{CL}$ & $29.90 \pm 0.577$ & $31.00 \pm 0.461$ & $32.20 \pm 0.513$ & $29.23 \pm 0.145$ & $14.94 * *$ \\
\hline $\mathrm{CB}$ & $11.60 \pm 0.057$ & $12.37 \pm 0.185$ & $12.60 \pm 0.057$ & $12.37 \pm 0.033$ & $14.25 * *$ \\
\hline $\mathrm{PL}$ & $23.47 \pm 0.088$ & $23.10 \pm 0.251$ & $22.50 \pm 0.251$ & $23.37 \pm 0.120$ & $4.07 \mathrm{~ns}$ \\
\hline PB & $9.20 \pm 0.057$ & $9.53 \pm 0.033$ & $10.0 \pm 0.057$ & $9.27 \pm 0.088$ & $5.71 *$ \\
\hline PW & $837.00 \pm 1.006$ & $837.73 \pm 1.072$ & $885.17 \pm 1.416$ & $868.80 \pm 0.737$ & $880.46 * *$ \\
\hline
\end{tabular}

$*=5 \%$ level of significance, $* *=1 \%$ level of significance, $n s=$ not significant.

\section{Results and Discussion}

Results on the effect of UV-radiation on different characters of silkworm variety, Urboshi-1 were presented in Table 1. Analysis of variance of the experimental data revealed that all the characters except larval mortality, silk cocoon ratio, pupal length and pupal breadth varied significantly due to UV-radiation exposed at pupal stage (Table 1), indicating that UVradiation can be effective in improving different economic traits of B. mori. Sengupta et al. (1973), Datta and Roy (1976) and Sengupta et al. (1977) also recorded positive results at low doses of irradiation to improve their local silkworm races through X-ray and $\gamma$ ray induced mutagenesis. But Faruki and Kundu (2005) reported negative effects on economic traits in $B$. mori due to UV-irradiation exposed at larval stage. Hosagoudar and Manjunatha (2006) reported positive and negative affects of Helium-Neon laser on B. mori at different stages of embryo. Similarly Kotani et al. 2002 stated that diapause eggs exposed to X-rays displayed significant differences in mutation in different doses however; no differences were observed for non diapause eggs. Earlier on Tazima (1978) also noted that sensitivity to radiation varies according to species, strains, individuals and even different stages of the same species. Dose dependent sensitivity of silkworm to different forms of ionizing radiation has also been reported by Sado (1963), Murakami and Kondo (1964), Molnar et al. (1964), Shankaranarayanan (1982), Singh et al. (1990), Hasan et al. (1998) and Faruki (2004). 
Table 4. Mean performance of different lines of $B$. mori in the $\mathrm{R}_{3}$ generation isolated from UV-irradiated pupae for different traits.

\begin{tabular}{|c|c|c|c|c|c|}
\hline \multirow[t]{2}{*}{ Traits } & \multicolumn{4}{|c|}{ Lines } & \multirow[t]{2}{*}{ F-values } \\
\hline & UI-DW & U1-LW & U10-LD & 0 (Control) & \\
\hline LW-3 & $113.63 \pm 0.845$ & $107.43 \pm 0.611$ & $99.23 \pm 0.433$ & $108.33 \pm 1.162$ & $60.34 * *$ \\
\hline LW-4 & $318.23 \pm 0.876$ & $351.10 \pm 0.608$ & $381.70 \pm 0.880$ & $367.10 \pm 1.517$ & $658.41 * *$ \\
\hline LW-5 & $478.77 \pm 3.989$ & $512.40 \pm 1.862$ & $518.33 \pm 1.424$ & $505.51 \pm 1.591$ & $38.21 * *$ \\
\hline LW-M & $1490.00 \pm 0.461$ & $1474.73 \pm 2.37$ & $1502.47 \pm 1.702$ & $1451.80 \pm 0.305$ & $253.55 * *$ \\
\hline LL-4 & $30.97 \pm 0.376$ & $33.66 \pm 0.277$ & $32.62 \pm 0.207$ & $28.98 \pm 0.290$ & $35.77 * *$ \\
\hline LL-5 & $46.93 \pm 0.317$ & $50.51 \pm 0.317$ & $51.43 \pm 0.088$ & $48.60 \pm 0.266$ & $46.81 * *$ \\
\hline LL-M & $41.03 \pm 0.384$ & $43.17 \pm 0.185$ & $45.33 \pm 0.088$ & $51.60 \pm 0.200$ & $892.14 * *$ \\
\hline LM & $30.67 \pm 0.666$ & $27.00 \pm 0.577$ & $21.67 \pm 1.666$ & $26.67 \pm 1.732$ & $12.62 * *$ \\
\hline $\mathrm{CW}$ & $931.67 \pm 0.520$ & $982.50 \pm 1.242$ & $1000.27 \pm 0.819$ & $969.20 \pm 0.808$ & $517.93 * *$ \\
\hline SW & $126.80 \pm 0.461$ & $131.73 \pm 0.959$ & $139.5 \pm 0.529$ & $121.43 \pm 0.617$ & $148.58 * *$ \\
\hline $\mathrm{SR} \%$ & $0.134 \pm 0.002$ & $0.138 \pm 0.002$ & $0.147 \pm 0.002$ & $0.125 \pm 0.001$ & $12.42 * *$ \\
\hline $\mathrm{CL}$ & $30.77 \pm 1.134$ & $30.53 \pm 0.260$ & $31.43 \pm 0.120$ & $29.77 \pm 0.120$ & $1.61 \mathrm{~ns}$ \\
\hline $\mathrm{CB}$ & $11.60 \pm 0.057$ & $12.37 \pm 0.272$ & $12.20 \pm 0.057$ & $12.27 \pm 0.145$ & $4.00 \mathrm{~ns}$ \\
\hline $\mathrm{PL}$ & $22.90 \pm 0.057$ & $22.67 \pm 0.088$ & $22.83 \pm 0.120$ & $23.06 \pm 0.066$ & $8.00 *$ \\
\hline PB & $9.23 \pm 0.577$ & $9.43 \pm 0.033$ & $9.67 \pm 0.339$ & $9.06 \pm 0.666$ & $2.22 \mathrm{~ns}$ \\
\hline $\mathrm{PW}$ & $834 \pm 0.814$ & $836.90 \pm 0.458$ & $881.57 \pm 0.405$ & $868.37 \pm 0.520$ & $4447.30 * *$ \\
\hline
\end{tabular}

$*=5 \%$ level of significance, $* *=1 \%$ level of significance, $n s=$ not significant, weight of $3^{\text {rd }}$ instar larvae $=\mathrm{LW}-3$, weight of $4^{\text {th }}$ instar larvae $=$ LW-4, weight of $5^{\text {th }}$ instar larvae $=$ LW-5, weight of mature larvae $=$ LW-M, length of $4^{\text {th }}$ instar larvae $=$ LL- 4 , length of $5^{\text {th }}$ instar larvae $=$ LL-5, length of mature larvae $=$ LL-M, larval mortality $=$ LM, weight of cocoon $=\mathrm{CW}$, weight of shell $=\mathrm{SW}$, shell ratio $=\mathrm{SR} \%$, length of cocoon $=\mathrm{CL}$, breadth of cocoon $=\mathrm{CB}$, length of pupa $=\mathrm{PL}$, breadth of pupa $=\mathrm{PB}$, weight of pupa $=\mathrm{PW}$.

It is interesting to note that UV-irradiated silkworms produced cocoons with heterogeneous shape and size. Depending on the variation in the shape and size of the cocoon three lines, viz. U1-DW, U1-LW and U10-LD were selected. The selected lines were again assessed and compared with that of the mean rearing performance of the control batches. Mean performances on cocoon and pupal characters of different lines are shown in Table 2. The differences among the lines were highly significant for majority of characters except shell ratio, cocoon breadth and pupal length.

The rearing performances of the selected lines in the $R_{2}$ and $R_{3}$ generations were presented in the Tables 3 and 4 , respectively. Analysis of variance showed highly significant result in all the characters except larval mortality (LM) and pupal length (PL) for $\mathrm{R}_{2}$ generation and cocoon length (CL), breadth (CB) and pupal length (PL) for $\mathrm{R}_{3}$ generation (Table 3). Results suggested that the shape and size of the selected lines persisted up to $\mathrm{R}_{3}$ generation.

Results of the final rearing in the $\mathrm{R}_{3}$ generation clearly indicate that the cocoon characters in the selected lines are much better than those of the control. The performance in respect of the cocoon characters of the selected lines showed that the line U10-LD was the best and the next one was U1-LD. The former also showed the lowest larval mortality. These advantages can be utilized in commercial rearing of the silkworms as the present results clearly indicate that UV-rays could be utilized as a potential source for improving the economic traits in B. mori.

\section{References}

Altenburg E. 1934. The artificial production of mutations by ultra-violet light. Am. Nat. 68: 491-567.

Aurbach C. 1976. Mutation research. Chamman and Hall, London. 1014pp.

Coulon M. 1969. Studies on X-ray damage in the early larvae of Bombyx mori L. Compt. Rend. Ser. D. 268: 959-62.

Datta PK and Roy GC. 1976. X-ray induced mutagenesis in silkworm. Ann. Res. and Adm. Report. 1: 11-12.

Faruki SI. 2004. Potency of ultra-violet radiation on the development and reproduction of the silkworm, Bombyx mori L. (Lepidoptera: Bombycidae). J. biosci. 12: 23-30.

Faruki SI and Kundu PK. 2005. Sensitivity of the silkworm, Bombyx mori L. (Lepidoptera: Bombycidae) larvae to UV-irradiation. Invertebr. Surv. J. 2: 75-81.

Gardner EJ and Snustad DP. 1981. Principles of Genetics (6 ${ }^{\text {th }}$ edn.). John Wiley and Sons Inc. New York 314-319 pp. 
Hasan M, Jahan MS and Khan AR. 1998. Effect of ultraviolet irradiation on the Uzi-fly, Exorista sorbillans Wiedmann, an endoparasitoid of the silkworm, L. Insect Sci. App. 18(1): 87-91.

Hosagoudar SR and Manjunatha HB. 2006. Impact of He-Ne laser on bio-commercial traits of silkworm, Bombyx mori L. Sericologia, 46: 1- 4.

Hosagoudar SR and Manjunatha HB. 2011. Picosecond UV laser induced morphological, biochemical and biological changes in Bombyx mori

Kotani E, Farusawa T, Nagaoka S, Nojima K, Fujii K, Sugimura Y, Ichida M, Suzuki E, Nagamatsu A, Todo $\mathrm{T}$ and Ikenaga M. 2002. Somatic mutation in the larvae of silkworm, Bombyx mori , induced by heavy inon irradiation to diapause eggs. J. Radiat. Res. 43: suppl., S193-S198.

Krishnaswami S. 1978. New technology of silkworm rearing. Central Silk Board, Bombay, India. 23 pp.

Levine L. 1980. Biology of the Gene ( $3^{\text {rd }}$ edn.). The C.V. Mosby Co. Chapter 13: 434-476.

Mallik MU, Hossain MM and Mollah SA. 1968. Preliminary study of the stimulating effect of low dose gamma-radiation on the larvae of silkworm, L. Nucl. Sci. App. 4: 7-10.

Molnar A, Gubieza A, and Babos L. 1964. A study of silkworms from the eggs of Bombyx mori L. irradiated with gamma rays. Ann. Bio. Tihany. 31: 50-54.

Murakami A and Kondo M. 1964. Relative biological effectiveness of $14 \mathrm{Mc} \mathrm{V}$-neutrons to gamma rays for inducing mutations in silkworm Bombyx mori, Gonia. Jpn. J. Gent. 39: 102-114.

Rahman MA. 1983. Technology of mulberry silkworm rearing suitable for the climatic condition in Bangladesh. Reshom 1: 71-79.
Sado T. 1963. Spermatogenesis of the silkworm and its bearing on radiation induced sterility, Part I. J. Fac. Agri. Kyushu University. 12: 359-385.

Sengupta K, Datta PK, Samaddar SK and Gongopdhyay A. 1973. Studies on mutagenesis in silkworm. Ann. Res. and Adm. Report. 1: 17-19.

Sengupta K, Datta PK and Das S. 1977. Gamma ray induced mutagenesis in silkworm for improvement of deteriorated evolved race D/14-B Ann. Res. and Adm. Report. 1:17-19.

Shankaranarayanan K. 1982. Genetic effects of ionizing radiation in multicellular eukaryotes and the assessment of genetic radiation hazards in man. Elsevior Biomedical Press, Amsterdam. Pp.83-85.

Singh R, Nagaraju J, Vijayaraghavan K and Premalatha V. 1990. Radiation sensitivity of the silkworm, Bombyx mori. Indian J. Seric. 29(1): 1-7.

Tazima Y. 1964. The genetics of the silkworm. Elck Boods Ltd. London. 253 pp.

Tazima Y. 1978. Radiation mutagenesis of the silkworm. In The Silkworm-an important Laboratory Tool. (ed. Tazima, Y). pp 213-245. Kodensha Ltd., Tokyo, Japan.

Tazima Y. 1983. Environmental mutagenesis: A view from the study of the silkworm. In Proc. XV Int. Cong. Genet. New Delhi, India. pp.43-52.

Tazima Y. 1984. Effect of dose rate and fractionated delivery of ionizing radiation on mutation induction in silkworm spermatogenesis. In Problems of Threshold in Chemical Mutagenesis. (ed. Tazima et al.). pp.169173. The Environmental Mutagen Society of Japan.

Manuscript received on 18 June 2011 and revised on 2 November 2011 